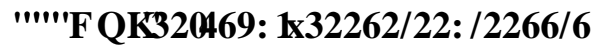

\title{
UNMANNED AERIAL VEHICLE USED FOR SECURITY OVER THE BALTIC SEA
}

\section{BEZZALOGOWY STATEK POWIETRZNY A BEZPIECZEŃSTWO NA MORZU}

\section{Mirosław Nowakowski, Dariusz Rykaczewski, Ryszard Sabak}

\author{
Air Force Institute of Technology \\ Instytut Techniczny Wojsk Lotniczych \\ 01-494 Warszawa $\square$ ul $\square$ Ks. Bolesława 6 \\ e-mails: mirosław.nowakowski@itwl,pl, dariusz.rykaczewski@itwl.pl, \\ ryszard.sabak@itwl.pl
}

\begin{abstract}
The paper presents new unmanned aerial vehicle (UAV) design for Regional and The Local Marine Fishery Inspectorates. Its specific design and maintenance specification allows to increase control abilities and will be the reason for increasing security of the sea sailing.
\end{abstract}

Keywords: UAV, technical object, engineering.

Streszczenie: W referacie przedstawiono nową konstrukcję bezzałogowego statku powietrznego dla Okręowych i Terenowych Inspektoratów Rybołówstwa Morskiego. Jego specyficzna konstrukcja i parametry eksploatacyjne pozwola na zwiększenie możliwości kontrolnych i spowodują wzrost bezpieczeństwa ruch statków na morzu.

Słowa kluczowe: BSP, obiekt techniczny, konstrukcja 


\section{UNMANNED AERIAL VEHICLE USED FOR SECURITY OVER THE BALTIC SEA}

Since many years rapid development of UAV's follows. It follows not only in military but also in civilian scope. The specific designs are made for police, border guard, foresters, geologists, geodesists. The basic advantage of it, as different to that used in military, are low cost of maintenance. That characteristic is the kea feature while designing UAV for Regional and The Local Marine Fishery Inspectorates and it enables to detect, monitor and track sea sailing and to see the situation on the sea to increase security of the sailing and to monitor illegal fishing.

Presented project consists of new demonstrator UAV design and testing to get maintenance experience and to precise detail requirements for UAV to introduce new methods for fishing monitoring by:

- implementation innovation methods of fishing security,

- reduction of negative effects of fishery on environmental,

- improving management and security over the sea board.

The UAV demonstrator system for detecting, monitoring and tracking sea sailing consists of the elements:

- UAV,

- camera and IR camera,

- data link,

- ground control station,

- take off and landing system,

- maintenance support.

Conception project has been presented on figure 1. The kea components are two air floats that allows landing on water. Movable watchhead has been presented on figure 2 . 


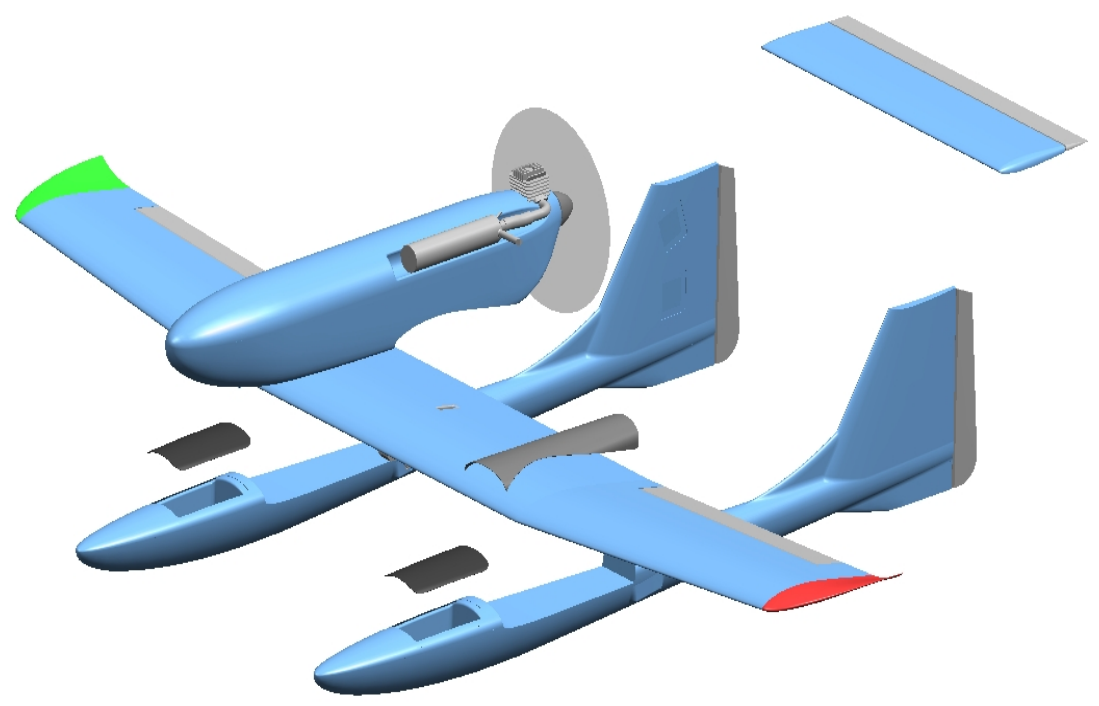

Fig. 1. Conception project

The UAV demonstrator specification are:

- on board take off or classical take off,

- autonomous or manual control,

- landing on board in net or on water,

- endurance: 1 hour and half minimum,

- height: up to $600 \mathrm{~m}$.,

- airspeed: $60 \mathrm{~km} / \mathrm{h}-120 \mathrm{~km} / \mathrm{h}$,

- wind strength: up to 7 degrees of Buford $(14 \mathrm{~m} / \mathrm{s}-17 \mathrm{~m} / \mathrm{s})$,

- radius of action: $20 \mathrm{~km}$ minimum,

- payload: movable watchhead with digital camera or IR camera,

- ability to collect data from camera,

- maintenance: 2 persons 


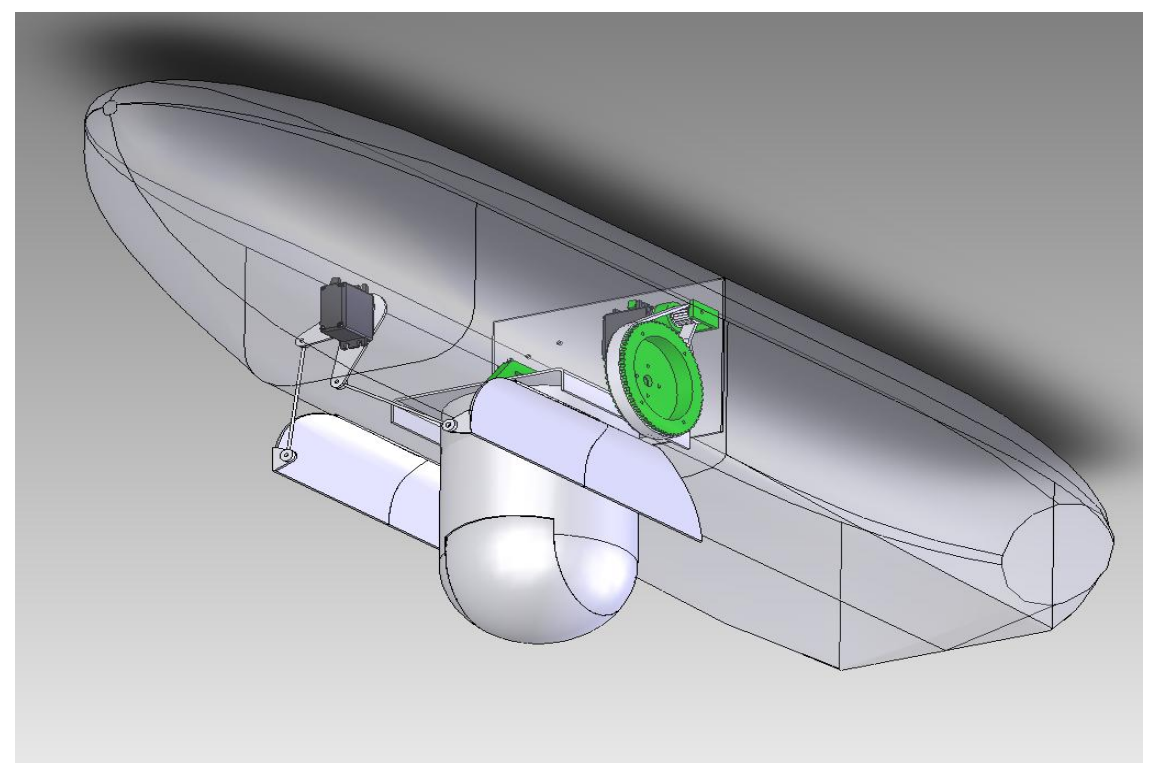

Fig. 2. Movable watchhead

The project is made in two stages:

Stage 1.

It includes UAV design and building of the system:

- two UAV's with engines, power supply and controls,

- controlled movable watchheads to enable watching down,

- onboard computers for automatic control,

- building computer software,

- building software for ground control station,

- down and up link,

- manual control,

- autonomous flight control,

- collecting data component,

- launcher and net landing component.

Stage 2.

The stage 2 includes testing on ground, flight tests and maintenance tests in sea conditions. The elements of that are:

- tests on ground and in flight to evaluate technical requirements, 
- tests in flight in the scope of the tactical usage to verify abilities and limitations of the system.

As the result of the project two UAV's has been built and flight tests has been taken. In the second stage of the project maintenance tests will be taken in a sea conditions with cooperation with Szczecin Maritime University.

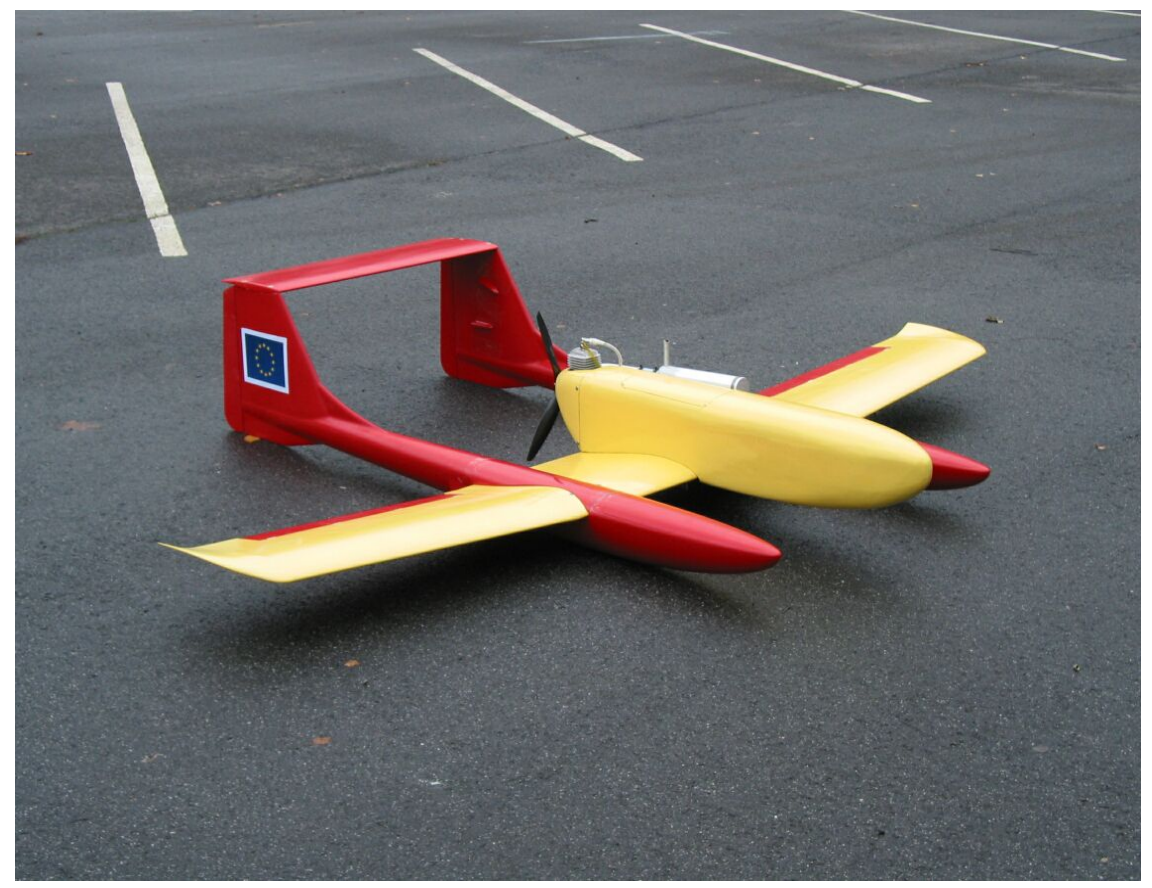

Fig. 3. UAV plane. 


\section{BEZZALOGOWY STATEK POWIETRZNY A BEZPIECZEŃSTWO NA MORZU}

Od wielu lat następuje szybki rozwój bezzałogowych statków powietrznych. Następuje on nie tylko w dziedzinie wojskowej, ale taż cywilnej. Opracowuje się specjalistyczne konstrukcje wykorzystywane przez policję, straż graniczną, leśników czy geologów i geodetów. Ich podstawową zaletą, w odróżnieniu od stosowanych w wojsku, są niskie koszty eksploatacji. Ta cech stała się również jedną $\mathrm{z}$ podstawowych przy powstawaniu demonstratora bezzałogowego statku powietrznego dla Okręgowych i Terenowych Inspektoratów Rybołówstwa Morskiego umożliwiającego w czasie prawie rzeczywistym wykrywanie, obserwowanie i dokumentowanie ruchu obiektów oraz zjawisk na morzu w celu podniesienia bezpieczeństwa ruchu statków rybackich i połowów .

Przedstawiony projekt zakładał opracowanie, wykonanie i przeprowadzenie badań funkcjonalnych demonstratora takiego systemu dla zdobycia doświadczeń eksploatacyjnych oraz określenie szczegółowych wymagań techniczno-funkcjonalnych na jego docelową wersję, w celu wprowadzenia nowoczesnych metod monitoringu łowisk poprzez:

- wdrożenie innowacyjnych metod zmierzających do ochrony łowisk;

- redukcję negatywnych skutków rybołówstwa na środowisko naturalne;

- poprawienie systemu zarządzania i ochrony zintegrowanej strefy brzegowej.

W skład demonstratora systemu bezzałogowego samolotu do wykrywania, obserwacji i dokumentowania obiektów oraz zjawisk na morzu wchodzą:

- statek powietrzny

- głowice obserwacyjne - aparat fotograficzny oraz kamera IR,

- układy transmisji danych telemetrycznych;

- stacja sterowania, kontroli lotu i analizy danych;

- układy startu i lądowania;

- wyposażenie eksploatacyjne.

Projekt koncepcyjny statku powietrznego przedstawiono na rys. 1. Charakterystyczne są dwa zamontowane pływaki umożliwiające wodowanie na morzu. Wysuwaną głowicę obserwacyjną przedstawiono na rys.2. 


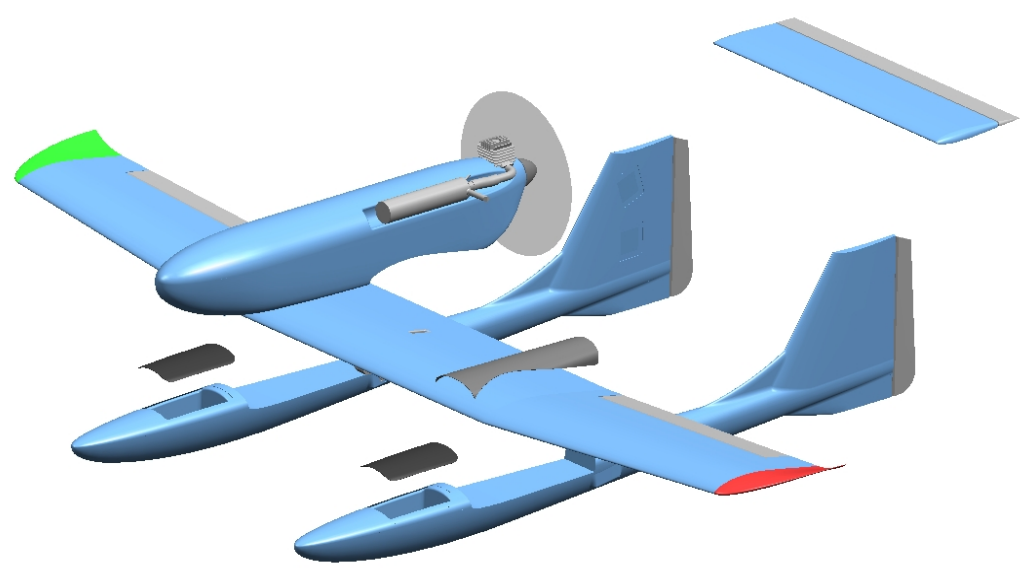

Rys. 1 Projekt koncepcyjny statku powietrznego

Demonstrator systemu ma spełniać następujące podstawowe, wstępnie określone wymagania techniczno-funkcjonalne:

- start - z pokładu statku morskiego lub z ziemi

- sterowanie i kontrola lotu - w trybie „ręcznym” (operator) i automatycznym;

- lądowanie - na statku (w siatkę wychwytową) lub na wodzie;

- czas lotu - min $1,5 \mathrm{~h}$;

- pułap lotu - do $600 \mathrm{~m}$;

- zakres prędkości lotu (IAS) - od $60 \mathrm{~km} / \mathrm{h}$ do $120 \mathrm{~km} / \mathrm{h}$;

- możliwość wykonywania zadań przy sile wiatru do $7^{0} \mathrm{~B}$ (ok. $14 \div 17$ $\mathrm{m} / \mathrm{s})$

- promień operowania - min. $20 \mathrm{~km}$;

- wyposażenie zadaniowe - wymienna głowica obserwacyjna z cyfrowym aparatem fotograficznym lub kamerą IR;

- możliwość archiwizacji danych z obserwacji powietrznej;

- obsługa - max. 2 osoby 


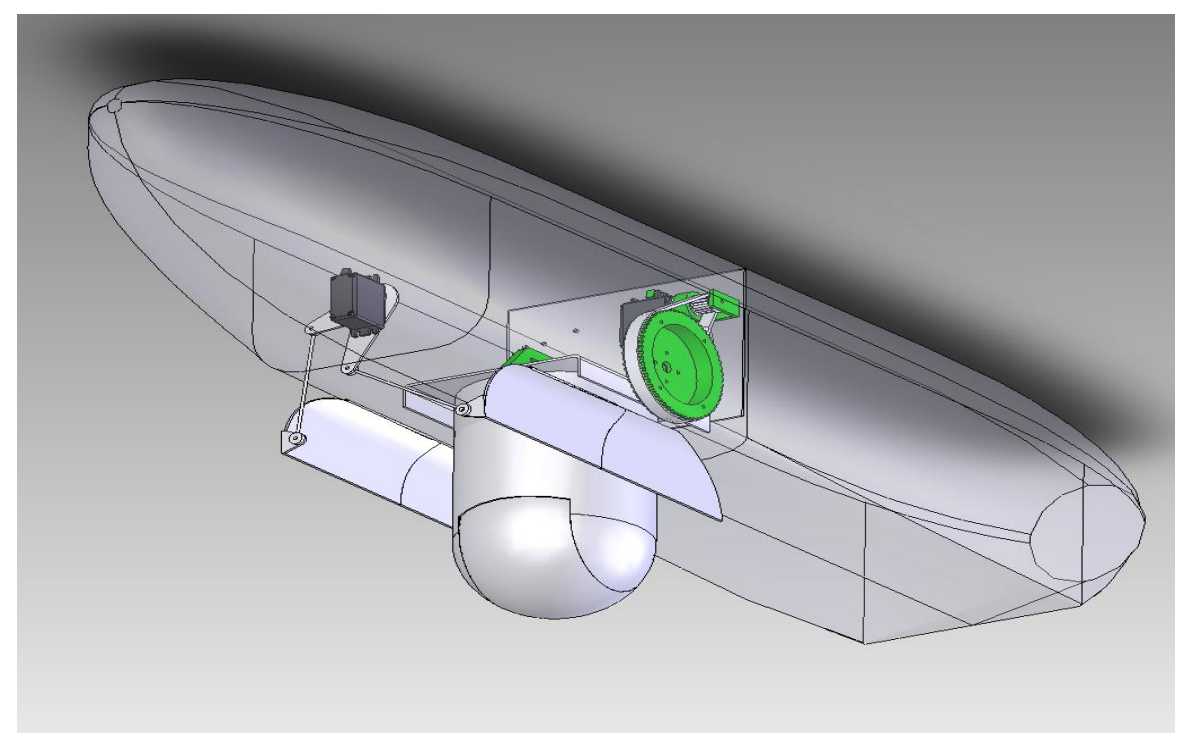

Rys.2. Głowica obserwacyjna

Projekt jest realizowany w 2 etapach:

Etap I obejmie między innymi opracowanie projektu i wykonanie elementów systemu:

- statków powietrznych z zespołami napędowym, układami zasilania oraz układami sterowania;

- sterowanych głowic obserwacyjnych umożliwiających obserwację dolnej półsfery statku powietrznego;

- komputerów pokładowych odpowiedzialnych za automatyczne sterowanie i kontrolę lotu statku powietrznego;

- modułu programowania komputera pokładowego;

- opracowanie oprogramowań stacji naziemnych;

- układu transmisji danych telemetrycznych i komend sterowania;

- modułu sterowania w trybie „ręcznym”;

- układu kontroli lotu w trybie automatycznym;

- układu wizualizacji i rejestracji danych z obserwacji powietrznej;

- układów wyrzutni startowej i siatki wychwytującej.

W etapie II przeprowadzone będą wstępne badania naziemne i w locie oraz testy funkcjonalne $\mathrm{w}$ warunkach morskich demonstratora systemu. Realizacja tego etapu obejmie między innymi: 
- przeprowadzenie badań naziemnych i w locie dla sprawdzenia spełnienia wymagań techniczno-funkcjonalnych;

- przeprowadzenie testów w locie w zakresie uzgodnionych scenariuszy wykorzystania systemu dla uzyskania danych o możliwościach i ograniczeniach wykonywania zadań kontrolno-morskich.

W wyniku realizacji projektu zbudowano (rys 3) i oblatano dwa statki powietrzne. W drugim etapie prac przy współudziale Akademii Morskiej w Szczecinie wykonane zostaną badania eksploatacyjne statków powietrznych oraz systemu w warunkach morskich..

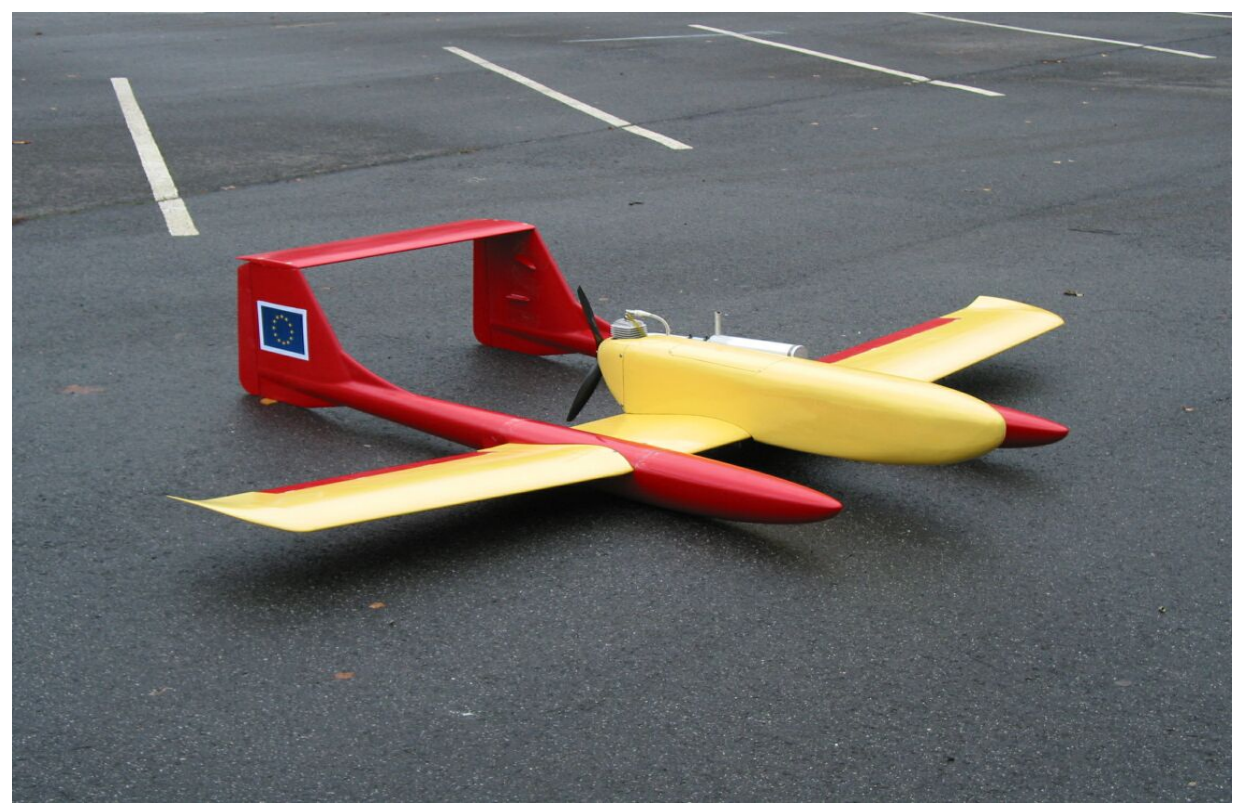

Rys. 3. Zbudowany statek powietrzny. 
Ph.D. RYKACZEWSKI Dariusz, Air Force Institute of Technology, Warszawa, lecturer, specialisation: machinery building, UAV's military engineering, research and development, command and control. Publications in field.

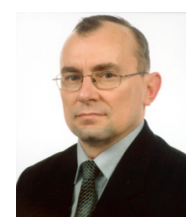

Ph.D. SABAK Ryszard, Air Force Institute of Technology, Warszawa, lecturer, specialisation: machinery building, UAV's military engineering, research and development,management. Publications in field.

Ph.D. NOWAKOWSKI Mirosław, Air Force Institute of Technology, Warszawa, specialisation: machinery building, research and development. Publications in field. 